\title{
DESIGN OF A (MINI) WIDE PLATE SPECIMEN FOR STRAIN-BASED WELD INTEGRITY ASSESSMENT
}

\author{
S. Hertelé ${ }^{1}$, W. De Waele ${ }^{2}$, R. Denys ${ }^{2}$ and M. Verstraete ${ }^{2}$ \\ ${ }^{1}$ FWO Aspirant, Ghent University, Laboratory Soete, Belgium \\ ${ }^{2}$ Ghent University, Laboratory Soete, Belgium
}

\begin{abstract}
Wide plate tension tests are commonly executed to investigate the integrity of defective welds under a uniaxial load. The specimen can be flat or curved, depending on the geometry from which it has been extracted (plate or pipe). Despite its usefulness, the design of the (curved) wide plate test is still not standardized up-to-date. This paper compares two specimen designs with a different length-to-width ratio through finite element analysis, using a design-of-experiments approach to account for different influential factors. The results reveal significant differences between the interpretation of tests with net section collapse and gross section collapse, promoted by weld strength overmatch. Further, both investigated designs tend to provide similar estimates of failure mode, strain capacity and crack driving force. Hence, the shorter specimen is considered an acceptable alternative to the slightly more representative longer specimen.
\end{abstract}

Keywords - weld, defect, strain-based design, wide plate specimen

\section{INTRODUCTION}

Weld defects are an unavoidable fact of life. Under installation or operation of welded structures, these defects can give rise to failure, possibly leading to economical or ecological disasters and/or casualties. To avoid catastrophic failure events, weld integrity has to be ensured on the basis of representative tests. The results of these tests allow to develop weld defect tolerance guidelines.

A wide range of small-scale weld integrity tests have been standardized (e.g. ASTM E1820-08a [1]). The extrapolation of small-scale test results to a full-scale structure, however, can be questionable. In the mid1950 's, Wells published on a medium-scale test, aiming to give a better representation of the actual size of the structure $[2,3]$. Originally focussing on flat plates, the application field of this so-called wide plate (WP) test was extended to curved plates (originating from pipelines), by Prof. Soete from Ghent University in 1979. Further exploring possibilities, the curved wide plate (CWP) test has since the 1990's evolved into a valuable tool to evaluate the strain capacity of defected pipeline girth welds [4].

A wide plate test can be described as a uniaxial tensile test on a (cooled) medium-scale sample of a plate or pipe, containing a defected weld or HAZ. The defect can either be natural or machined. To mount the specimen in the test rig and apply the tensile load, it is welded to two end blocks ('heads'), which requires end 'shoulders' to achieve a gradual transfer of load from the head to the actual prismatic part of the specimen ('body') (Fig. 1). Conventional (curved) wide plate tests mostly have a prismatic width around 300 $\mathrm{mm}$. A test sample with a significantly lower prismatic width $($ e.g. $150 \mathrm{~mm}$ ) is often referred to as a 'mini' (curved) wide plate specimen.

Despite being a useful tool to estimate the strain capacity of plastically deformed welded structures, the (curved) wide plate test is not yet standardized. As a consequence, specimen geometry, instrumentation and test procedure have to be carefully designed in order to obtain a meaningful test result. A particular point of attention is the length-to-width ratio $(L / W)$ of the body of the specimen. This ratio has to be large enough to ensure a zone of uniform longitudinal strain [5], enabling a proper measurement of remotely applied strain [6] and leading to representative failure strains [7]. Reported in all three aforementioned studies [5-7] is a minimum $L / W$-ratio of 3 . This ratio is also advised in the recently published UGent guidelines for curved wide plate testing [8].

This paper discusses and compares finite element results of mini wide plate tension tests performed on two possible specimen designs (with a different $L / W$-ratio), developed for a specific tensile test rig. Section 2 briefly describes the test rig limitations that were taken into account for the specimen designs. Next, Section 3 elaborates the performed finite element simulation programme. Results and their discussion are presented in Section 4. Conclusions are finally drawn in Section 5. 


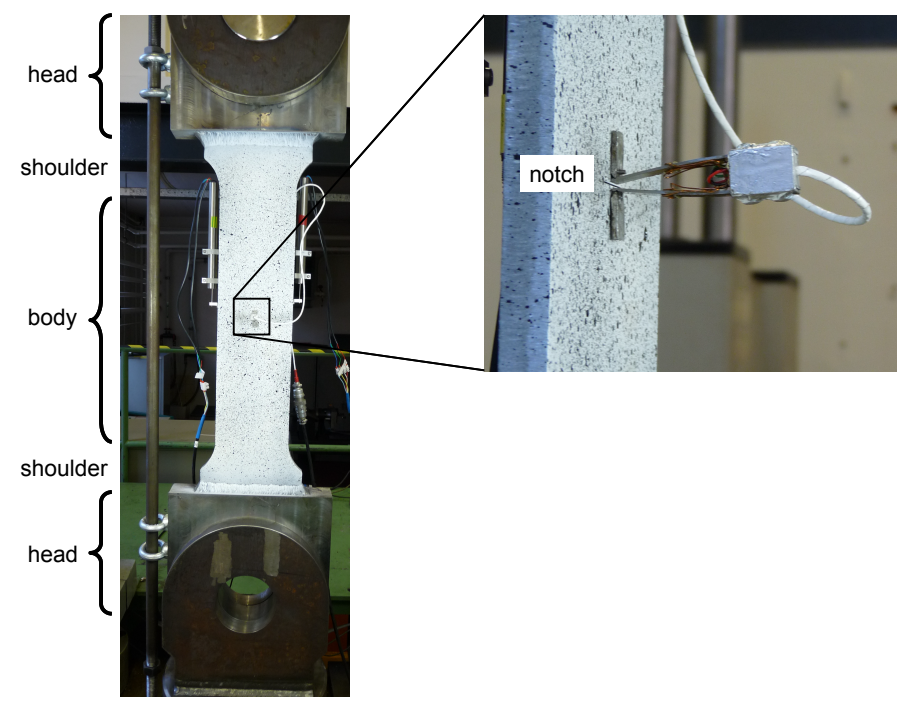

Figure 1. Configuration of a mini wide plate tension test.

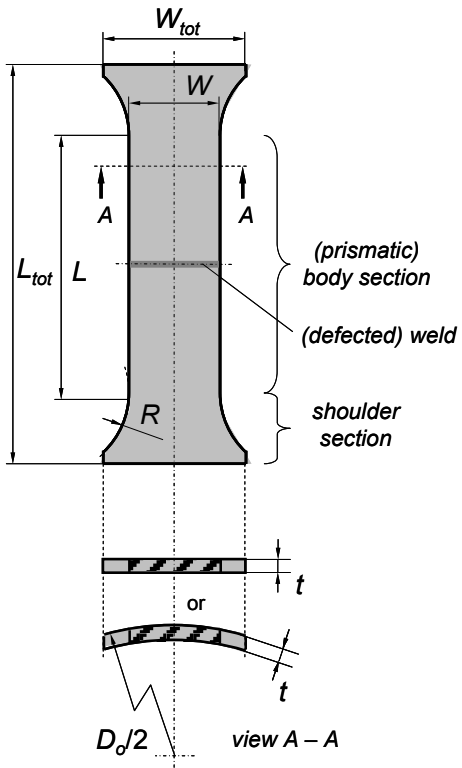

Figure 2. Geometry of a (mini) wide plate specimen.

\section{TEST COUPON DESIGN: LIMITATIONS OF TENSILE TEST RIG}

The geometry of a (mini) wide plate specimen can be symbolized as in Fig. 2. In terms of test interpretation, the body width $W$ is the most important parameter. A wider specimen gives a closer approximation of the actual (full-scale) structure, since more material surrounds (restrains) the investigated defect. However, when it comes to establishing an appropriate body width $W$, two test rig limitations have to be taken into account. First, tensile force is restricted by the capacity of the test rig. For a same level of applied tensile stress, the required tensile force will increase as $W$ increases. Second, specimen length $L_{\text {tot }}$ is restricted by the dimensional limitations of the test rig. Aiming to have a sufficient $L / W$-ratio, this indirectly implies a limitation on $W$.

The abovementioned restrictions have been applied on a $2500 \mathrm{kN}$ universal test rig owned by Laboratory Soete, resulting in the following rules of thumb for mini wide plate tests with a plate thickness $t<20 \mathrm{~mm}$ and linepipe steel grades according to API 5L [9]:

- steel grades API 5L X80 and lower:

$$
\begin{aligned}
& W=150 \mathrm{~mm} ; \\
& W=130 \mathrm{~mm} .
\end{aligned}
$$$$
\text { - steel grade API } 5 \mathrm{~L} \text { X100: }
$$

\section{FINITE ELEMENT MODELLING}

To investigate possible specimen designs for Laboratory Soete's $2500 \mathrm{kN}$ universal test rig, finite element modelling has been applied. As noted in Section 1, an essential geometric variable to investigate is the body's length-to-width ratio $L / W$. This section describes a parametric finite element script which has been used to investigate two mini wide plate designs with $W=150 \mathrm{~mm}$ and a different $L / W$-ratio. A first subsection focuses on the structure of the finite element models. Secondly, the performed simulation programme is elaborated. Results are discussed in Section 4. It is worth mentioning that a companion paper provides an experimental validation of the finite element model [10].

\subsection{Finite element script}

A script, in-house developed using the open-source programming language Python, communicates with the finite element software package ABAQUS ${ }^{\circledR}$ 6.9. It creates models that represent (mini) wide plate specimens. The following paragraphs focus on the structure of the created models and the analysis of simulation results. 


\subsubsection{Structure of the created models}

The script creates models that represent one half of a wide plate specimen, assuming transversal symmetry. First, a simplified geometry is created (flat plate, weld with vertical fusion lines, simplified defect shape) which is then modified to its final shape using node coordinate transformations. This technique allows to systematically modify important geometrical features, such as plate curvature, weld and defect shape, to the user's desire.

The specimen is connected to two rigid end blocks, both of which are impeded to rotate. The tensile load is then applied by translating one of the end blocks while keeping the other end block fixed in space.

A large-deformation formulation ('nlgeom') has been used. Such formulation is required to obtain realistic deformation patterns in the specimen, and realistic tensile force calculations. All materials have been modelled as rate-independent elastic-plastic, and were assumed to harden isotropically according to the Von Mises yield criterion.

The finite element models consist of three-dimensional solid linear brick elements with reduced integration (ABAQUS ${ }^{\circledR}$ element type 'C3D8R'). Analysis duration was optimized by choosing a deliberate mesh density for all regions of the specimen, obtained through a mesh convergence study. In total, the models from the current study contained between 9602 and 17602 elements. An initially blunt defect (tip radius $75 \mu \mathrm{m}$ ) with a sufficiently fine spider-web mesh around the defect tip was modelled. Stable crack initiation and subsequent crack growth has not been included in the model. Fig. 3 shows an example model created by the Python script, including a detail of the near-defect mesh. Note that this example illustrates the possibility to obtain a curved plate, a weld with deliberate fusion line geometry and weld cap reinforcement, and a semi-elliptical defect (of which only one half is modelled due to symmetry). Also note that, for the investigated curved wide plates, the notch was placed at the inner-diameter surface.

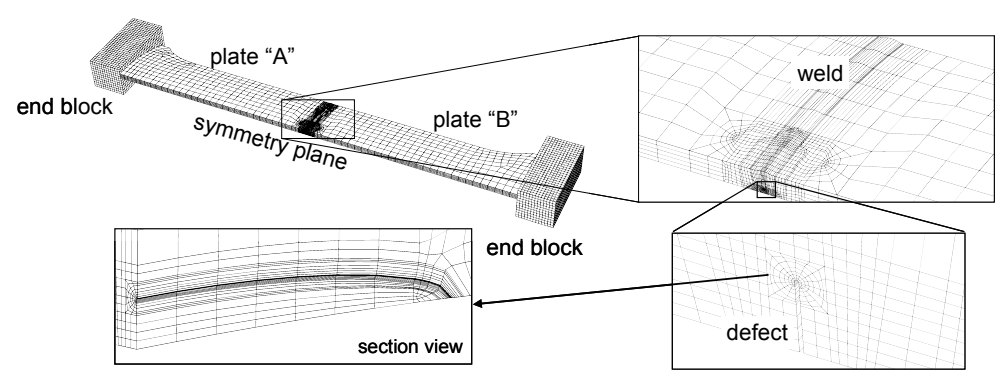

Figure 3. An example finite element model of a (curved) wide plate, created by the Python script.

\subsubsection{Analysis of results}

A first, evident analysis consisted of studying the distributions of stresses, displacements and strains throughout the entire specimen. Second, tensile force $F$ has been extracted. Finally, deformations have been investigated at three levels:

- at the level of the defect, crack mouth opening displacement (CMOD) has been extracted as a measure of crack driving force (the urge of a crack to grow in a stable or unstable way);

- at a plate-specific level, the so-called remote strain $e_{r}$ has been extracted. Remote strains for both plates ("A" and "B", Fig. 3) were simulated to be obtained from two "small" LVDTs, placed at the transversal mid-plane of each plate;

- at a global level, the so-called overall strain $e_{o}$ has been extracted. $e_{o}$ was obtained from a "large" LVDT which traverses the defected weld. According to common practice for curved wide plate tests, the extension of the overall strain LVDT was arbitrarily compensated with CMOD as in $[7,8]$.

The specific positions and gauge lengths of the LVDTs are discussed in more detail in Section 3.2.

From these results, the strain capacity of the investigated wide plate, $e_{o, \max }$, is arbitrarily determined as the overall strain corresponding with maximum tensile force. This event can be related to the onset of necking in the weld section ('net section collapse') or in the gross section, away from the weld ('gross section collapse'). Other similar definitions (e.g. based on remote strain, or overall strain without a compensation with CMOD) may be more appropriate to better represent the failure event in the full-scale structure, but this discussion is outside the scope of the current paper. 
Noteworthy is that, despite the choice to define strain capacity on the basis of overall strain, the actual event of failure (i.e. maximum tensile force) was for the simulations that failed due to net section collapse easier to visualize in a plot of CMOD as a function of remote strain. For these simulations, where CMOD increases in an unstable way, the maximum tensile force roughly corresponds with the maximum remote strain (Fig. 4(a)). This was observed not necessarily to be the case for the maximum overall strain (Fig. $4(\mathrm{~b}))$.

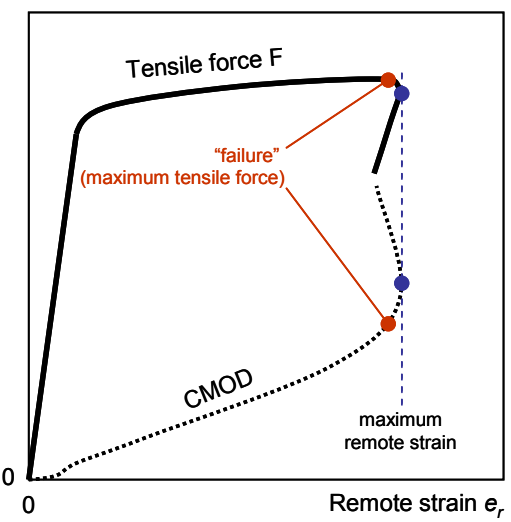

(a)

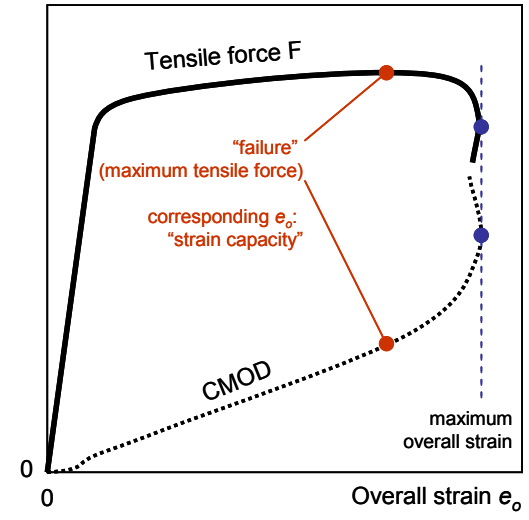

(b)

Figure 4. The analysis of a result with net section collapse is more intuitive in terms of remote strain:

(a) Failure approximately corresponds to the maximum remote strain.

(b) Failure (strain capacity) does not necessarily correspond to the maximum overall strain.

\subsection{Simulation programme}

Two specimen designs (geometry and instrumentation), both of which are suitable for the $2500 \mathrm{kN}$ test rig mentioned in Section 2, have been compared (Fig. 5). A "shorter" wide plate specimen (Fig. 5(a)) has an $L / W$-ratio of 3.3, whereas a "longer" wide plate specimen (Fig. $5(\mathrm{~b}))$ has an $L / W$-ratio of 5.3. The latter approximates the $L / W$-ratio of standardized small-scale prismatic tension test specimens (e.g. ASTM E8M-04 [11]: $L / W=5.6$ ), and is considered more representative for a uniaxial wide plate test. Nevertheless, it requires more sampling material, and is therefore less practical in use (preparation of specimen, transport, mounting, execution of test).

(a)

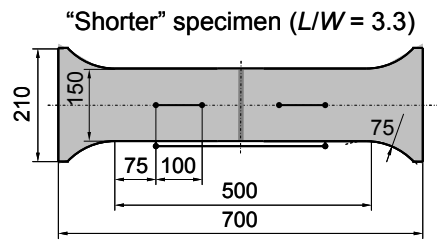

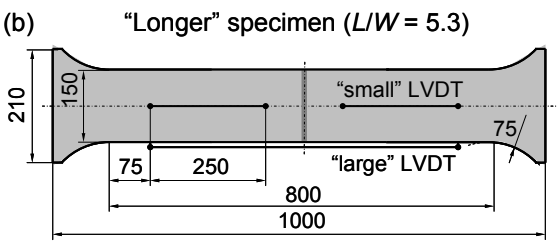

Figure 5. Two specimen designs are considered in the presented study.

For each design, five dimensionless parameters have been varied between two levels (a lower value "-" and a higher value "+") as summarized in Table 1. This allows to investigate the influence of material properties, plate geometry and defect size.

As regards the material properties, it can be noted that many modern pipeline steels exhibit a two-stage strain hardening behaviour which cannot be described by most common stress-strain models. To address this shortcoming, the authors developed a new "UGent" stress-strain model [12] which gives a better representation of the stress-strain curves of these pipeline steels $[13,14]$. Since the influence of the exact stress-strain curve shape is not to be neglected in strain-based design [15], the UGent model is generally advised over other models.

In comparison with most common stress-strain equations, the UGent model has the advantage of increased accuracy, but the disadvantage of an increased number of parameters. Since the aim of this specific study was to obtain general trends rather than exact information on the influence of material properties, it was chosen not to represent material behaviour by the the UGent model but by the more straightforward Ramberg-Osgood [16] equation, which is also readily available in ABAQUS ${ }^{\circledR}$. Applied on true stress $\sigma$ $(\mathrm{MPa})$ and true strain $\varepsilon(-)$, this equation is given by: 


$$
\varepsilon=\frac{\sigma}{E}+0.002\left(\frac{\sigma}{\sigma_{0.2}}\right)^{n}
$$

where $E$ is Young's modulus (MPa), $n$ the strain hardening exponent (-) and $\sigma_{0.2}$ the $0.2 \%$ proof stress (MPa). $n$ can be uniquely related to the yield-to-tensile ratio $Y / T(-)$ of the material, defined as the ratio between $0.2 \%$ proof stress and ultimate tensile stress. It also determines the uniform elongation $e_{m}$ (strain corresponding with ultimate tensile stress in a uniaxial small-scale tensile test). $Y / T$-values corresponding to the chosen $n$-values are also given in Table 1. The properties of the heat-affected zones were assumed to be equal to those of the base metal. Further, weld and base metal have been given the same strain hardening exponent, but possibly different $0.2 \%$ proof stresses related on the basis of yield strength overmatch $O M_{Y S}(\%)$ :

$$
O M_{Y S}=\left(\frac{\sigma_{0.2, \text { weld }}-\sigma_{0.2, \text { base }}}{\sigma_{0.2, \text { base }}}\right) \cdot 100 \%
$$

Both designs have been investigated using a design-of-experiments (DOE) approach, reducing the number of simulations for each design to 16. Since two designs have been investigated, the total number of simulations was 32 . Note that a full-factorial simulation programme would have required $2^{5}$ or 32 simulations per design, or 64 simulations in total. According to DOE theory, the simulation matrix has a resolution five, which means that all effects of single parameters and all possible coupled effects can be identified. Table 2 shows the parameter settings for all simulations, "-" and "+" referring back to the values in Table 1.

Apart from the five varied parameters, some other parameters have been kept fixed for all simulations:

- $\quad 0.2 \%$ proof stress of base metal: $\sigma_{0.2, \text { base }}=500 \mathrm{MPa}$;

- weld geometry: root opening $5 \mathrm{~mm}$, bevel angle $10^{\circ}$ (defined as the angle between a fusion line and the through-thickness direction), no weld cap reinforcement;

- defect depth: $3 \mathrm{~mm}$ (common for weld defects).

\begin{tabular}{|c|c|c|c|}
\hline Parameter & Symbol (dimension) & Low value (“-") & High value ("+") \\
\hline Yield strength overmatch & OMYS (\%) & 0 & 20 \\
\hline \multirow{2}{*}{$\begin{array}{l}\text { Strain hardening } \\
\text { exponent }\end{array}$} & \multirow{2}{*}{$n(-)$} & 15 & 25 \\
\hline & & $(Y / T \approx 0.85)$ & $(Y / T \approx 0.93)$ \\
\hline \multirow{2}{*}{$\begin{array}{l}\text { Plate outside diameter / } \\
\text { plate thickness }\end{array}$} & \multirow{2}{*}{$D_{o} / t(-)$} & 40 & $\infty$ \\
\hline & & (curved plate) & (flat plate) \\
\hline \multirow{2}{*}{ Relative defect depth } & \multirow{2}{*}{ alt $(-)$} & 0.15 & 0.30 \\
\hline & & $(t=20 \mathrm{~mm})$ & $(t=10 \mathrm{~mm})$ \\
\hline \multirow{2}{*}{ Relative defect length } & \multirow{2}{*}{$2 c / W(-)$} & 0.17 & 0.33 \\
\hline & & $(2 c=25 \mathrm{~mm})$ & $(2 c=50 \mathrm{~mm})$ \\
\hline
\end{tabular}

Table 1: Values given to the five parameters, included in the parameter study.

\begin{tabular}{|c|c|c|c|c|c|c|c|c|c|c|c|c|c|c|c|c|}
\hline \multirow[b]{2}{*}{ Parameter } & \multicolumn{16}{|c|}{ Parameter set nr. } \\
\hline & 1 & 2 & 3 & 4 & 5 & 6 & 7 & 8 & 9 & 10 & 11 & 12 & 13 & 14 & 15 & 16 \\
\hline$O M_{Y S}$ & - & - & - & - & - & - & - & - & + & + & + & + & + & + & + & + \\
\hline$n$ & - & - & - & - & + & + & + & + & - & - & - & - & + & + & + & + \\
\hline$D_{o} / t$ & - & - & + & + & - & - & + & + & - & - & + & + & - & - & + & + \\
\hline$a / t$ & + & - & + & - & + & - & + & - & + & - & + & - & + & - & + & - \\
\hline $2 c / W$ & + & - & - & + & - & + & + & - & - & + & + & - & + & - & - & + \\
\hline
\end{tabular}

Table 2: Parameter matrix. 


\section{RESULTS AND DISCUSSION}

The results and their discussion are divided into two parts. First, Section 4.1 discusses the influence of all varied parameters (Tables 1 and 2) on the outcome of the simulation, specifically for the specimen design with $L / W=3.3$ (Fig. 5(a)). Then, Section 4.2 focuses on the influence of specimen design (Fig. 5(a) vs. Fig. $5(b))$ on all obtained results.

\subsection{Influence of investigated parameters}

Table 3 summarizes the observed failure mode and strain capacity (absolute and relative, defined as strain capacity divided by the uniform elongation of the base metal) for all simulations. All simulations with $O M_{Y S}$ $=0 \%$ (parameter sets 1 to 8 ) failed due to net section collapse, whereas all simulations with $O M_{Y S}=20 \%$ (parameter sets 9 to 16) showed gross section collapse. Clearly, the defects in the overmatching welds are to some extent shielded from the remotely applied deformation, whereas this is not the case for the evenly matching welds. This is illustrated in Fig. 6, which compares the simulations with parameter sets 1 and 11 for an equal level of remote strain $\left(e_{r}=0.03\right)$.

Table 3: Observed failure modes and strain capacities for the specimen design with $L / W=3.3$.

\begin{tabular}{|c|c|c|c|c|c|c|c|}
\hline $\begin{array}{l}\text { Parameter } \\
\text { set nr. }\end{array}$ & $\begin{array}{l}\text { Failure } \\
\text { mode }\end{array}$ & $\begin{array}{c}\text { Strain } \\
\text { capacity } \\
e_{o, \max }(-) \\
\end{array}$ & $\begin{array}{c}\text { Relative strain } \\
\text { capacity } \\
e_{o, \max } / e_{m}(-)\end{array}$ & $\begin{array}{c}\text { Parameter } \\
\text { set } \mathrm{nr} \text {. }\end{array}$ & $\begin{array}{l}\text { Failure } \\
\text { mode }\end{array}$ & $\begin{array}{c}\text { Strain } \\
\text { capacity } \\
e_{o, \max }(-) \\
\end{array}$ & $\begin{array}{c}\text { Relative strain } \\
\text { capacity } \\
e_{o, \max } / e_{m}(-)\end{array}$ \\
\hline 1 & \multirow{8}{*}{$\begin{array}{c}\text { Net } \\
\text { section } \\
\text { collapse }\end{array}$} & 0.037 & 0.51 & 9 & \multirow{8}{*}{$\begin{array}{l}\text { Gross } \\
\text { section } \\
\text { collapse }\end{array}$} & 0.067 & 0.91 \\
\hline 2 & & 0.064 & 0.87 & 10 & & 0.066 & 0.91 \\
\hline 3 & & 0.055 & 0.76 & 11 & & 0.066 & 0.91 \\
\hline 4 & & 0.060 & 0.82 & 12 & & 0.067 & 0.92 \\
\hline 5 & & 0.029 & 0.65 & 13 & & 0.039 & 0.87 \\
\hline 6 & & 0.034 & 0.76 & 14 & & 0.038 & 0.87 \\
\hline 7 & & 0.016 & 0.36 & 15 & & 0.040 & 0.91 \\
\hline 8 & & 0.036 & 0.82 & 16 & & 0.038 & 0.86 \\
\hline
\end{tabular}

(a) $O M_{Y S}=0 \%$

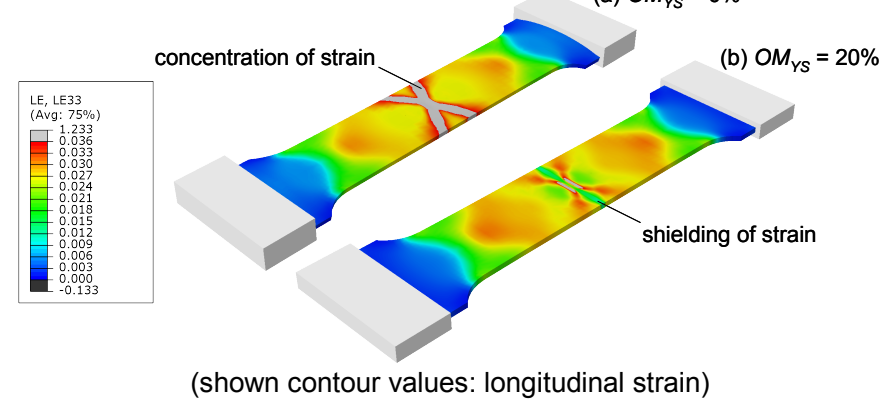

Figure 6. A weld which is overmatched in strength $(b-$ parameter set 11$)$ shields the weld defect from applied deformations, which is not the case for an evenly matching weld ( $a-$ parameter set 1$)$.

Because the mechanism behind net section collapse is fundamentally different from that behind gross section collapse, both are separately discussed below.

\subsubsection{Failure due to net section collapse (OMYS $=0 \%$, parameter sets 1 to 8$)$}

To analyse the left half of Table 3, Fig. 7(a) shows the average strain capacities for all simulations where one of the four parameters $Y / T$ (or $n$ ), $2 c / W, D_{o} / t$ or alt has a fixed value ("low" or "high"). Likewise, Fig. 7(b) depicts average relative strain capacities. The following observations can be made:

- $\quad D_{o} / t$ has no significant effect on (relative) strain capacity. This indicates that the results of a flat wide plate and a (mini) curved wide plate with similar properties (apart from plate curvature) are comparable. The distinction between flat and curved plates is further neglected.

- $\quad Y I T$ has a pronounced effect on strain capacity. This effect is not only due to the dependency of uniform elongation $e_{m}$ on $Y / T$, since the relative strain capacity is also - albeit less pronounced influenced.

- A relatively larger defect (higher a/t and/or higher $2 c / W$ ) results in lower (relative) strain capacities. This is logical since defect size influences the net (defective) cross section, where failure eventually occurs. The influence of alt appears to be more pronounced than the influence of $2 c / W$. 
Focusing on the evolution of CMOD prior to failure, the influence of $Y / T$ is different from the effects of $2 c / W$ and alt. Whereas YIT does not necessarily have a significant influence on the CMOD response before initiation of net section collapse (Fig. 8), $2 c / W$ and alt have an effect on CMOD at all strain levels (Fig. 9). To this respect, the influence of $2 c / W$ seems to increase as a/t increases (compare Fig. 9(b) with Fig. 9(a)).

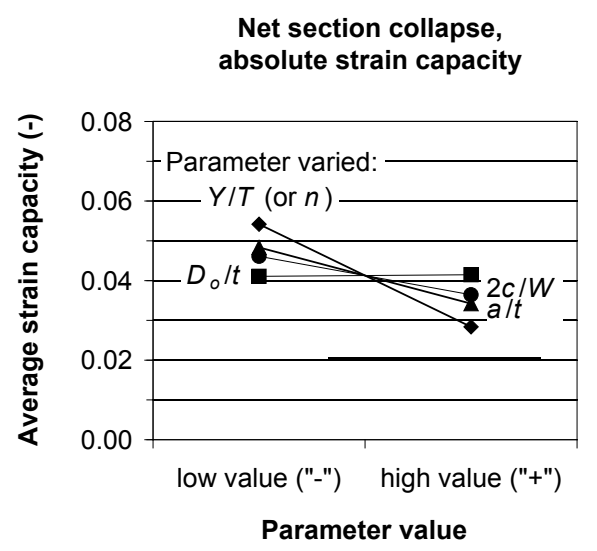

(a)

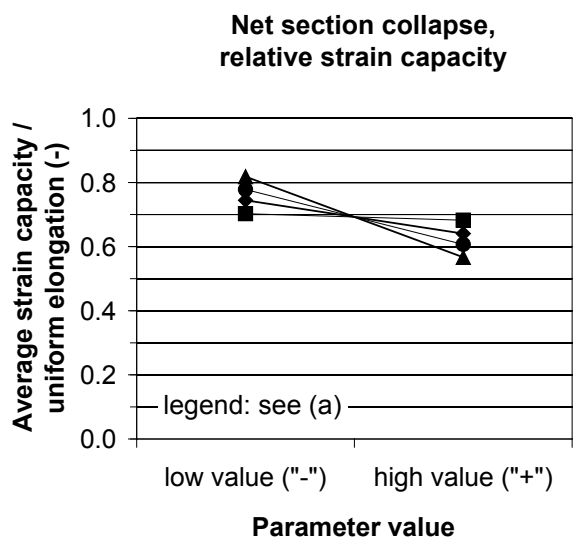

(b)

Figure 7. Averagely obtained (a) strain capacities and (b) relative strain capacities, for the simulations with net section collapse $\left(O M_{Y S}=0 \%\right)$.

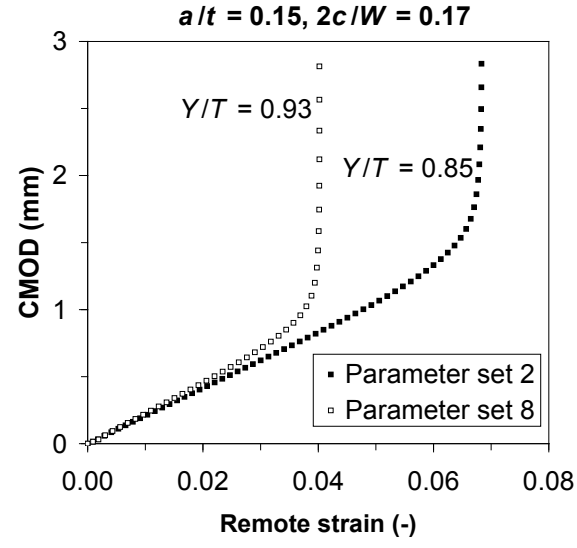

(a)

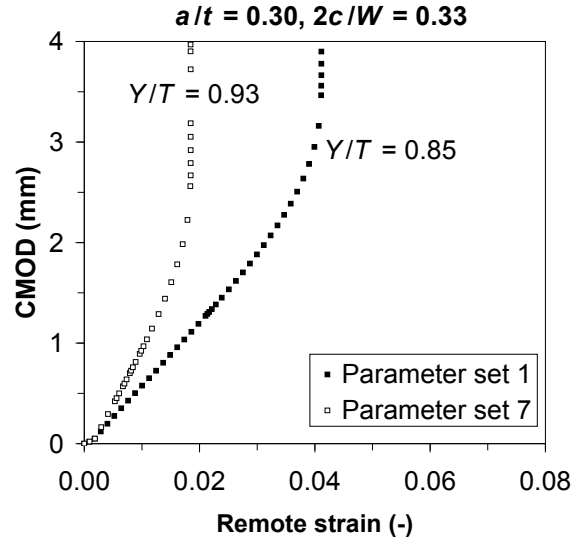

(b)

Figure 8. YIT has a pronounced influence on strain capacity. As regards the CMOD response prior to net section collapse, its influence is significant for large defects (b), but marginal for small defects (a).

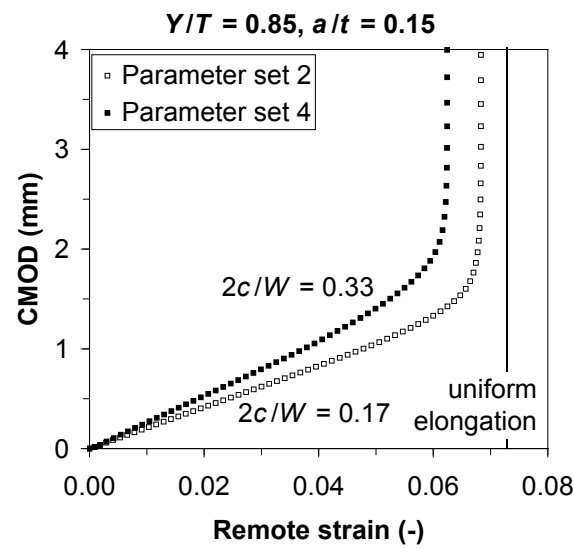

(a)

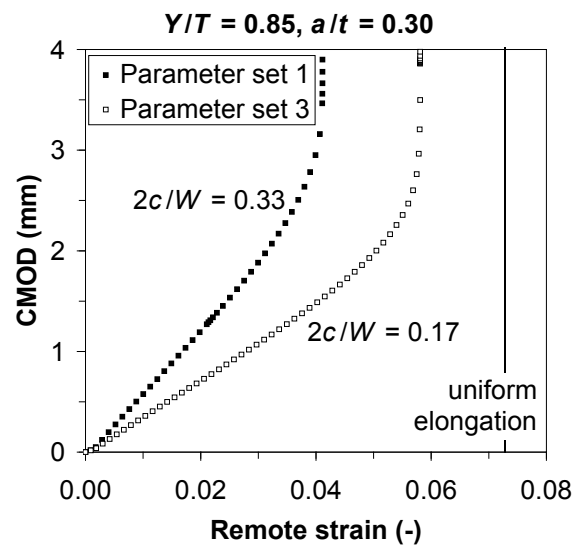

(b)

Figure 9. alt and $2 c / W$ have an influence on both strain capacity and CMOD response prior to net section collapse. The influence of $2 c / W$ is more pronounced for higher alt-values (b) than for lower alt-values (a). 
The influence of $2 c / W$ and alt throughout the entire deformation history is reflected in the development of plastic yielding near the defect. Whereas larger defects (high a/t, high 2c/W) encourage the occurrence of ligament (i.e. the material "above" the defect) yielding prior to yielding in the entire net section (Fig. 10(a)), smaller defects tend to synchronise both yielding stages (Fig. 10(b)).

$$
\begin{aligned}
& \text { white }=\text { no yielding } \\
& \text { black }=\text { yielding }
\end{aligned}
$$

(a)

Deep defect, long defect (= large defect)

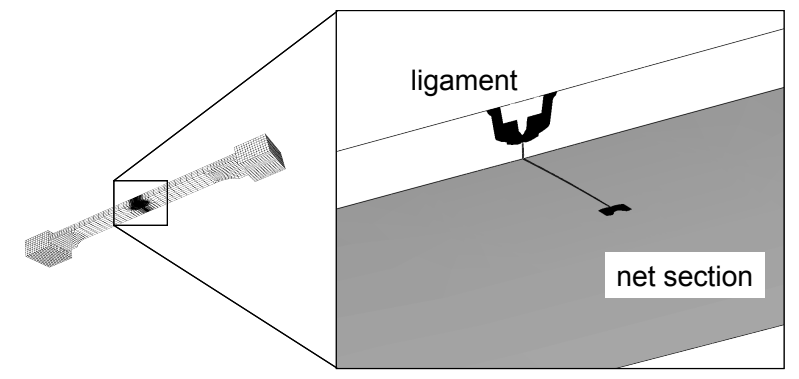

(b)

Shallow defect, short defect (= small defect)

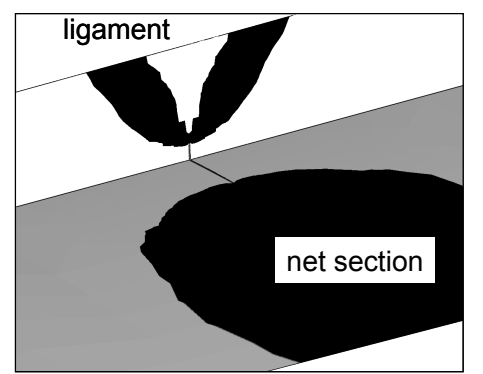

Figure 10. (a) A large defect promotes ligament yielding prior to section yielding (parameter set nr. 1). (b) A small defect stimulates a synchronous ligament and net section yielding (parameter set nr. 2). Both plots represent the first observation of ligament yielding.

\subsubsection{Failure due to gross section collapse $\left(O M_{Y S}=20 \%\right.$, parameter sets 9 to 16)}

Completely similar to Fig. 7, the right half of Table 3 (gross section collapse) is analyzed in Figs. 11(a) and (b). In comparison with net section collapse, $D_{o} / t$ is also of no importance here. On the other hand, significant differences can be observed. In particular, if gross section collapse occurs, strain capacity is only strongly influenced by $Y / T$ and not by $2 c / W$ or a/t. Nevertheless, even the effect of $Y / T$ becomes marginal in terms of relative strain capacity. For all simulations with gross section collapse, the strain capacity approximates the uniform elongation of the base metal. This is to be expected, since gross section collapse involves necking in this base metal, which similarly defines the uniform elongation in a small-scale base metal tension test.

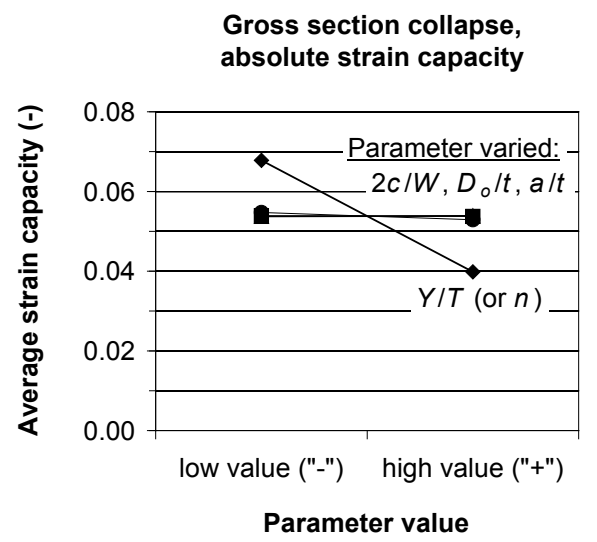

(a)

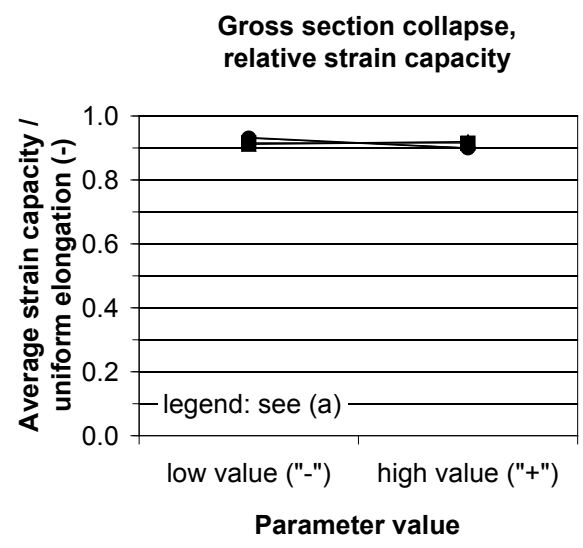

(b)

Figure 11. Averagely obtained (a) strain capacities and (b) relative strain capacities, for the simulations with gross section collapse $\left(O M_{Y S}=20 \%\right)$.

Despite the strong correspondence between strain capacity and uniform elongation in the case of gross section collapse, the CMOD response is determined by more parameters including relative defect length $2 c / W$ and depth a/t (Fig. 12). Similar to the case of net section collapse (Section 4.1.1), the influence of $2 c / W$ appears to increase as a/t increases. Note that the simulation with a/t $=0.30$ and $2 c / W=0.33$ was ended prematurely due to convergence problems. Nevertheless, a maximum load had occurred just before the simulation was stopped, and a strain capacity could consequently be derived. 


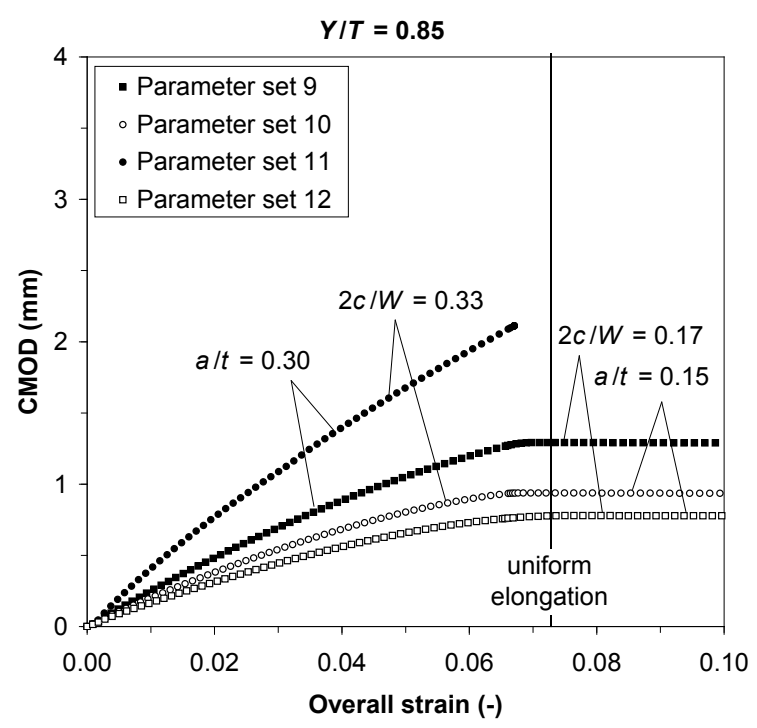

Figure 12. The CMOD response of wide plate tests that show gross section collapse is influenced by the shape and dimensions of the defect.

\subsection{Influence of specimen design}

Comparing the obtained results for both specimen designs ( $L / W=3.3$ and $L / W=5.3$, Fig. 5), the following has been observed:

- both designs result in the same failure mode for all investigated parameter sets (net section collapse if $O M_{Y S}=0 \%$, gross section collapse if $O M_{Y S}=20 \%$ );

- focussing on specimens that fail due to net section collapse, both designs were found to produce similar relative strain capacities: on average, $e_{o, \max } / e_{m}$ was 0.70 for $L / W=3.3$ and 0.69 for $L / W=$ 5.3). For each parameter set, the CMOD responses corresponding to both designs closely approximate each other, an example of which is shown in Fig. 13.

- focussing on specimens that fail due to gross section collapse, the longer specimen $(L / W=5.3)$ was found to produce strain capacities that closer approximate the base metal's uniform elongation $e_{m}$ : on average, $e_{o, \max } / e_{m}$ was 0.89 for $L / W=3.3$ and 0.94 for $L / W=5.3$. This effect was found more pronounced for base metals with a higher Y/T-ratio (Fig. 14), which is in accordance with literature [7]. The effect of specimen design on the CMOD response before necking was found to be highly limited, the difference between both being comparable to cases of net section collapse (e.g. Fig. 13).

Summarizing the above, both specimen designs give similar CMOD responses for net and gross section collapse. In the case of net section collapse, both specimen designs indicate similar strain capacities. In the case of gross section collapse, the shorter specimen conservatively promotes slightly lower strain capacities, whereas the longer specimen gives a better approximation of the base metal's uniform elongation. Nevertheless, the relevance of the observed differences between the shorter and the longer specimen in Fig. 14 can be discussed, since:

- the uniform elongation of many steels, especially high-strength steels with a high Y/T-ratio, is by nature prone to a high amount of scatter due to challenges in the control of the manufacturing process;

- even without natural scatter, the strain capacity of wide plate specimens that fail due to gross section collapse can be highly sensitive to unavoidable noise peaks of the acquired load signal. This anomaly is due to the flatness of the $F-e_{o}$ curve near the point of maximum load $[6,7]$.

From this consideration, the easier-to-handle shorter specimen design is considered to be a suited alternative to the more representative longer specimen design. 


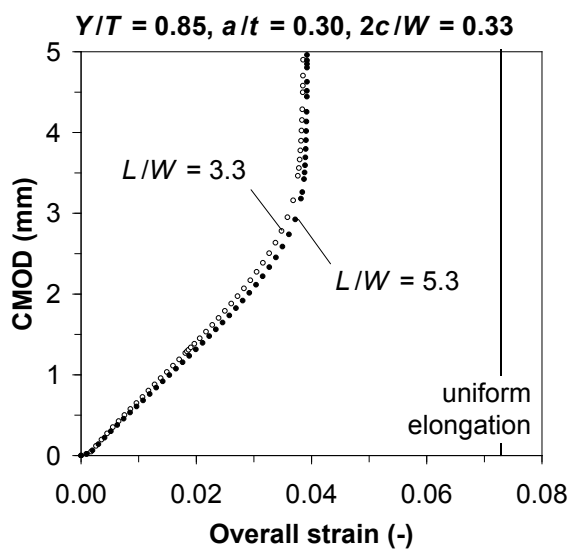

Figure 13. Both specimen designs result in a similar CMOD response.

(example result according to parameter set nr. 1)

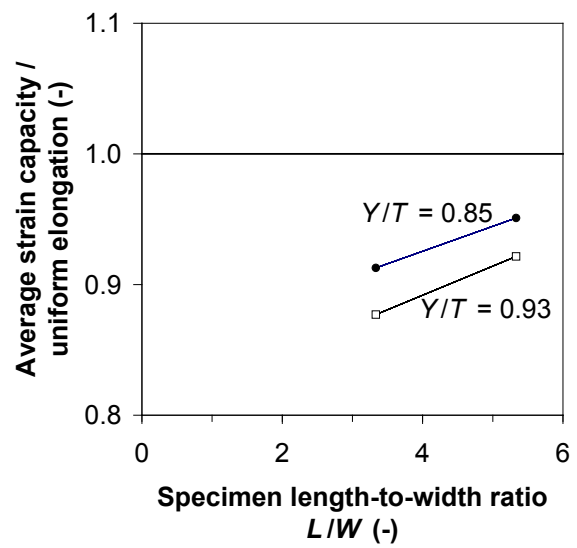

Figure 14. If failure is due to gross section collapse, strain capacity approximates the base metal's uniform elongation for longer specimens.

\section{CONCLUSIONS}

The dimensional and structural limitations of the test rig in which a (mini) wide plate test is performed play an important role in the specimen design. Both impose restrictions to the maximum allowable specimen width $W$, which have led to concrete guidelines for a particular test rig. Starting from these guidelines, two possible specimen designs with a same body width $W$ but different body length $L$ have been compared through finite element analysis. For the simulations performed in this study (see Section 3.2), the following conclusions can be drawn:

- Weld strength overmatch is a key factor governing the failure mode of a (mini) wide plate test. Whereas an evenly matching weld shows net section collapse, a high weld strength overmatch promotes gross section collapse.

- In the case of failure due to net section collapse, strain capacity is influenced by the base metal's yield-to-tensile ratio $Y / T$ and defect geometry and size $(a / t, 2 c / W$. alt and $2 c / W$ also alter the CMOD response prior to net section collapse and the distribution of plasticity originating from the notch. The influence of YIT on the CMOD response vanishes for smaller defects.

- The strain capacity of specimens that fail due to gross section collapse is strongly related to the base metal's uniform elongation. Similar to net section collapse, the CMOD response is also influenced by $2 c / W$ and $a / t$.

- Plate curvature was of no significant influence to the strain capacity of the investigated simulations.

- Both investigated specimen designs give similar CMOD responses and strain capacities under equal conditions (overmatch, $Y / T, 2 c / W$, alt). Hence, the shorter specimen - which is easier to handle - is advised over the longer specimen.

Note that, while providing useful trends, these conclusions may have to be adjusted to account for stable crack growth, which has not been included in the model.

\section{NOMENCLATURE}

\begin{tabular}{lll|lll}
$a$ & defect depth & $\mathrm{mm}$ & $L_{\text {tot }}$ & specimen total length & $\mathrm{mm}$ \\
$2 c$ & defect length & $\mathrm{mm}$ & $n$ & strain hardening exponent & - \\
$\mathrm{CMOD}$ & crack mouth opening displacement & $\mathrm{mm}$ & OMYS & yield strength overmatch of weld & $\%$ \\
$D_{o}$ & plate outer diameter (if curved) & $\mathrm{mm}$ & $t$ & plate thickness & $\mathrm{mm}$ \\
$e_{m}$ & uniform elongation & - & $R$ & specimen shoulder radius & $\mathrm{mm}$ \\
$e_{o}$ & overall strain & - & $W$ & specimen body width & $\mathrm{mm}$ \\
$e_{o, m a x}$ & strain capacity & - & $W$ & specimen maximum width & $\mathrm{mm}$ \\
$e_{r}$ & remote strain & - & $Y / T$ & yield-to-tensile ratio & - \\
$E$ & Young's modulus & $\mathrm{MPa}$ & $\varepsilon$ & true strain & - \\
$F$ & tensile force & $\mathrm{N}$ & $\sigma$ & true stress & $\mathrm{MPa}$ \\
$L$ & specimen body length & $\mathrm{mm}$ & & &
\end{tabular}




\section{ACKNOWLEDGEMENTS}

The authors would like to acknowledge the FWO - Vlaanderen (Fund for Scientific Research - Flanders) for its financial support (grant nr. 1.1.880.09N).

\section{REFERENCES}

[1] ASTM E1820 08a, Standard Test Method for Measurement of Fracture Toughness, ASTM International, 2008.

[2] Wells, A.A., The brittle fracture strengths of welded steel plates, Transactions of the Institution of Naval Architects, 93, 296-326, 1956.

[3] Wells, A.A., A 600-ton test rig for brittle fracture research, British Welding Journal, 3(1), 25.

[4] Denys, R., Lefevre, A., De Baets, P., A rational approach to weld an pipe material requirements for a strain based pipeline design, International Conference on Application and Evaluation of High-Grade Linepipes in Hostile Environments, Yokohama, Japan, 121-158, 2002.

[5] Wang, Y.Y., Liu, M., Chen, Y., Horsley, D., Effects of geometry, temperature, and test procedure on reported failure strains from simulated wide plate tests, Proceedings of the 6th International Pipeline Conference, Calgary, Alberta, Canada, Paper nr. IPC2006-10497, 2006.

[6] Hertelé, S., De Waele, W., Denys, R., Van Wittenberghe, J., Verstraete, M., Investigation of pipe strain measurements in a curved wide plate specimen, Proceedings of the 8th International Pipeline Conference, Calgary, Alberta, Canada, Paper nr. IPC2010-31292, 2010.

[7] Fairchild, D.P., Cheng, W., Ford, S.J., Minnaar, K., Biery, N.E., et al., Recent advances in curved wide plate testing and implications for strain-based design, International Journal of Offshore and Polar Engineering, 18, 161-170, 2008.

[8] Denys, R., Lefevre, A., UGent guidelines for curved wide plate testing, Proceedings of the 4th Pipeline Technology Conference, Ostend, Belgium, 2009.

[9] API 5L, Specification for Line Pipe, 42nd edition, American Petroleum Institute, 2000.

[10] De Keyser, K., Van Acker, F., Hertelé, S., Verstraete, M., De Waele, W., Denys, R., Validation of a wide plate finite element model using digital image correlation, Proceedings of the 3rd Conference on Sustainable Construction and Design, Ghent, Belgium, 2011.

[11] ASTM E8M 04, Standard Test Methods for Tension Testing of Metallic Materials, ASTM International, 2004.

[12] Hertelé, S., De Waele, W., Denys, R., A generic stress-strain model for metallic materials with twostage strain hardening behaviour, Accepted for publication in International Journal of Non-Linear Mechanics, doi:10.1016/j.ijnonlinmec.2010.12.004.

[13] Hertelé, S., Denys, R., De Waele, W., Full-range stress-strain relation modelling of pipeline steels, Journal of Pipeline Engineering, 8, 213-221, 2009.

[14] Hertelé, S., De Waele W., Denys, R., Determination of full range stress-strain behavior of pipeline steels using tensile characteristics, Proceedings of the $8^{\text {th }}$ International Pipeline Conference, Calgary, Alberta, Canada, Paper nr. IPC2010-31291, 2010.

[15] Hertelé, S., De Waele, W., Denys, R., Verstraete, M., Sensitivity of plastic response of defective pipeline girth welds to the stress-strain behavior of base and weld metal, Accepted for the 30th International Conference on Ocean, Offshore and Arctic Engineering, Rotterdam, The Netherlands, Paper nr. OMAE2011-49239, 2011.

[16] Ramberg, W., Osgood, W.R., Description of stress-strain curves by three parameters. National Advisory Committee for Aeronautics, Technical note No. 902, 1943. 